\title{
Factors associated with the duration of disability benefits claims among Canadian workers: a retrospective cohort study
}

\author{
Sohail M. Mulla PhD, Sun Makosso-Kallyth PhD, Nathalie St-Hilaire, Katrena Munsch MSc, Peter B. \\ Gove MSW, Diane Heels-Ansdell MSc, Gordon H. Guyatt MD MSc, Jason W. Busse DC PhD
}

\section{Abstract}

Background: Disability insurance protects workers from total loss of income in case of a disabling injury or illness by providing wagereplacement benefits. To better inform early identification of claims at risk of prolonged recovery, we explored predictors of the duration of disability benefits claims.

Methods: We conducted a retrospective cohort study using claims data provided by SSQ Life Insurance Company Inc., a private Canadian disability insurer. We examined all claims SSQ approved for short- and long-term disability benefits from Jan. 1, 2007, to Mar. 31, 2014, and evaluated the association between 9 variables and duration of short- and long-term disability benefits using Cox proportional hazards regression analyses.

Results: For both short- ( $n=70776)$ and long-term disability $(n=22$ 205) claims, and across all disorders, older age, female sex, heavy job demands, presence of comorbidity, attending an independent medical evaluation, receipt of rehabilitation therapy and longer time to claim approval were associated with longer claim duration. Higher predisability salary was associated with longer shortterm disability claim duration. Quebec residency was associated with longer short-term disability claim duration among workers with psychological disorders, but shorter short-term disability claim duration among those with musculoskeletal complaints and other illnesses. For long-term disability claims, however, residing in Quebec was associated with shorter claim duration, although the size of the association differed across clinical conditions.

Interpretation: The factors we found to be associated with the duration of short- and long-term disability claims may be helpful to identify claims at risk of prolonged recovery. Our study has limitations, however, and well-designed prospective studies are needed to confirm our findings and identify other promising predictors.

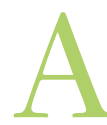

ccording to the 2012 Canadian Survey on Disability, about 3.8 million Canadians aged 15 years and older ( $13.7 \%)$ reported a disability. ${ }^{1}$ Disabilities often create barriers for participation in the labour force, and the resulting financial implications can be substantial, especially when absences from work are protracted. ${ }^{2,3}$ Although workers' compensation plans are mandatory in Canada, they do not provide coverage for all workers or for non-workrelated injuries or illnesses (e.g., injuries acquired outside of work, diabetes, rheumatoid arthritis). Employees wishing to obtain coverage for disabling injuries or illnesses not covered by compensation boards can purchase disability benefits through private for-profit providers. In Canada, short-term disability benefits plans typically provide wage-replacement benefits for 17 or 26 weeks. Long-term disability coverage begins when short-term disability benefits run out, with most policies providing coverage up to age 65 , as long as claimants remain disabled from their own occupation for the initial 2 years of the claim, and disabled from any and all occupations for which they are qualified by training or experience after they have been on claim for 2 years. Insurance companies monitor claimants' medical conditions and, should they improve to the point where claimants no longer meet the definition of disability, terminate payments.

Competing interests: Jason Busse reports grants from Mitacs Accelerate Graduate Research Internship Program, during the conduct of the study; personal fees from Prisma Health Canada, outside the submitted work; and he has developed and validated the Somatic PreOccupation and Coping (SPOC) Questionnaire, which is an instrument that identifies patients at high risk of prolonged disability. Sohail Mulla received a Mitacs Accelerate Doctoral Award that was partially funded by SSQ Financial Inc. No other competing interests were declared.

This article has been peer reviewed.

Correspondence to: Sohail Mulla, mullasm@mcmaster.ca

CMAJ Open 2017. DOI:10.9778/cmajo.20160027 
We have previously reported, in a study conducted in partnership with Sun Life Financial Canada, several administrative, clinical and demographic factors associated with the duration of disability benefits claims among workers with depression. ${ }^{4}$ It remains uncertain, however, whether these associations are consistent among other private insurers and other clinical conditions. This question is important to address, because understanding of factors associated with claim duration - particularly those that are modifiable may help insurers optimize case management policies and processes to facilitate faster recovery. Hence, we sought, using data from another private Canadian disability insurer - SSQ Life Insurance Company Inc. — to identify factors associated with disability benefits duration among Canadian workers.

\section{Methods}

\section{Standardized reporting}

We followed the Strengthening the Reporting of Observational studies in Epidemiology statement. ${ }^{5}$

\section{Design and setting}

We conducted a retrospective cohort study using claims data provided by SSQ Life Insurance Company Inc. (hereafter referred to as SSQ), the parent company of SSQ Financial Group and comprises 3 affiliates - SSQ General Insurance Company Inc., SSQ Insurance Company Inc., and SSQ Realty Inc. SSQ Financial Group offers a range of financial products and services across Canada, including traditional group plans for health insurance, prescription drug insurance, disability insurance, compassion insurance, life insurance, dental care insurance, health spending accounts and travel insurance. In addition to offering standard short- and longterm disability benefit plans, SSQ offers additional disability plans, which may be paid simultaneously or subsequently to the standard plans. The additional plans differ from standard plans with respect to several factors, including financial (e.g., lower or greater portion of predisability salary paid) or administrative (e.g., shorter or longer duration to change in disability definition date).

\section{Source of data}

We examined all claims SSQ approved for short- and longterm disability benefits from Jan. 1, 2007, to Mar. 31, 2014, which represented the most recent consecutive period for which SSQ collected data consistently and for which data were available electronically.

\section{Outcomes}

Our primary outcomes were the durations of short-term and long-term disability claims.

\section{Statistical analysis}

For our analyses, we considered claimants who received only short-term disability benefits, only long-term disability benefits, or both short- and long-term disability benefits for the same disability from SSQ. If a claimant received both short- and long-term benefits for the same disability, so long as each plan was only of 1 type (i.e., either standard or additional), that claimant contributed once in each short- and long-term disability model.

Guided by our previous study ${ }^{4}$ and content experts on our team, we selected, a priori, 10 variables that may be associated with claim duration and predicted the direction of anticipated effects (Appendix 1, available at www.cmajopen.ca/content/5/1/ E109/suppl/DC1). Claimants for whom SSQ manages both short- and long-term disability benefit plans do not undergo a separate approval process for long-term disability; rather, there is no delay between moving from short-term to long-term benefits as long as claimants qualify. For such claimants, we used the duration of claim approval for the short-term disability plan that SSQ recorded in its database, and imputed a value of 0 days to represent the duration of approval for the corresponding long-term disability plan. We considered 2 variables attendance at an independent medical evaluation arranged by SSQ and receipt of rehabilitation service funded by SSQ - as time-varying covariates to account for when they were initiated during the course of the disability claim.

We screened all data to identify implausible values, inconsistencies and missing data. When we identified implausible values and inconsistencies, we worked with SSQ to correct the data. We report the mean and standard deviation (SD) of normally distributed continuous variables, the median and interquartile range for continuous variables not normally distributed and, for categorical variables, number of occurrences as percentages.

We tested for pair-wise correlations between independent variables using a correlation matrix; if the Pearson correlation coefficient $(r)$ was greater than 0.80 for 2 variables, we removed the variable that we deemed of lesser importance. This situation arose once: claimants' province of residence and the office at which the claims were received were highly correlated $(r=0.89$ for short-term disability model; $r=0.93$ for long-term disability model). Administrators at SSQ advised that they were more interested in province of residence, owing to the potential influence of provincial differences in health care services and legislature affecting claims. Accordingly, we removed the claim office variable from our models, leaving us with 9 variables. For the remaining variables, we tested for multicollinearity by calculating the variance inflation factors associated with each independent variable in our models, and considered values of 5 or greater to indicate the presence of multicollinearity; associated variance inflation factors were all less than 2 .

We performed time-to-event analyses using Cox proportional hazards regression models to assess the association between the independent variables and duration of short- and long-term disability benefits. Our event was cessation of disability benefits. For short-term disability claims that were receiving benefits for 17 weeks (the most common short-term disability benefit plan duration administered by SSQ) after claim approval, we used 118 days (17 wk minus $1 \mathrm{~d}$ ) as our censoring point; for long-term disability claims, we used the date of extraction as our censoring point. To avoid overfitting, we required 10 or more events per variable for our Cox regression 
models. ${ }^{6}$ We excluded independent variables with fewer than 200 observations, unless we were able to collapse them with other related variables to exceed this threshold. To confirm that the proportional hazards assumption was met for each variable in our model, we calculated its interaction with time, while entering the remaining variables in the model without interactions. Statistical tests conducted when a data set is very large may, however, show statistical significance when the size of effect is trivial. Therefore, when an interaction was significant, we calculated the hazard ratios (HRs) at different time points, as follows: short-term disability - 30 and 90 days; long-term disability - 180, 365 (1 yr) and 548 days $(2.5 \mathrm{yr})$; if the HRs did not differ by 0.20 or greater across the time points, we did not consider the proportional hazards assumption to be violated. We calculated HRs for our analyses, their associated $99 \%$ confidence intervals (CIs), and associated $p$ val- ues. To minimize the likelihood of spurious findings, we considered an independent variable as statistically significant if it had a $p$ of less than 0.01 in each final adjusted model.

We conducted post-hoc analyses to explore whether independent variables were consistently predictive of duration of short- and long-term disability benefits across clusters of clinical conditions. We conducted our analyses for each of 3 subgroups of claimants, according to predefined classifications of illness or injury: ${ }^{1}$ psychological disorders, ${ }^{2}$ musculoskeletal complaints ${ }^{3}$ and other clinical conditions (the 5 most common conditions contributing to our analyses are shown in Appendix 2, available at www.cmajopen.ca/content/5/1/E109/suppl/DC1). For each variable in our models, we calculated its interaction with clinical condition, while entering the remaining variables in the model without interactions. When an interaction was significant, we compared the HRs across the clinical subgroups for substantial

\section{Table 1: Baseline characteristics of short- and long-term disability claims and claimants}

\begin{tabular}{|c|c|c|}
\hline Variable & $\begin{array}{c}\text { Short-term disability, } \\
\text { no. }(\%)^{\star}\end{array}$ & $\begin{array}{l}\text { Long-term disability, } \\
\text { no. }(\%)^{*}\end{array}$ \\
\hline Total claims & 70776 & 22205 \\
\hline Age of claimant, median (Q1-Q3), yr & $46(36-53)$ & $48(40-54)$ \\
\hline \multicolumn{3}{|l|}{ Sex } \\
\hline Male & 31068 (43.9) & $10052(45.3)$ \\
\hline Female & $39708(56.1)$ & $12153(54.7)$ \\
\hline Monthly salary, median (Q1-Q3), \$ & $3695.5(2915.5-4546.5)$ & $3521.8(2799.8-4546.5)$ \\
\hline \multicolumn{3}{|l|}{ Job demands } \\
\hline Sedentary & 22586 (31.9) & $8104(36.5)$ \\
\hline Light & $30217(42.7)$ & $8604(38.8)$ \\
\hline Heavy & $17973(25.4)$ & $5497(24.8)$ \\
\hline \multicolumn{3}{|l|}{ Province of residence } \\
\hline Quebec & $59117(83.5)$ & $16700(75.2)$ \\
\hline Other & $11659(16.5)$ & $5505(24.8)$ \\
\hline \multicolumn{3}{|l|}{ IIlness } \\
\hline Psychological disorder & $15294(21.6)$ & $7325(33.0)$ \\
\hline Musculoskeletal complaint & 22124 (31.3) & $7165(32.3)$ \\
\hline Other & 33358 (47.1) & $7715(34.7)$ \\
\hline \multicolumn{3}{|l|}{ Comorbidity } \\
\hline Yes & $10381(14.7)$ & $6447(29.0)$ \\
\hline No & 60395 (85.3) & $15758(71.0)$ \\
\hline \multicolumn{3}{|c|}{ Attendance at SSQ-arranged independent medical evaluation† } \\
\hline Yes & $1341(1.9)$ & $2275(10.3)$ \\
\hline No & $64435(98.1)$ & $19930(89.8)$ \\
\hline \multicolumn{3}{|l|}{ Receipt of SSQ-funded rehabilitation† } \\
\hline Yes & $1098(1.6)$ & $2552(11.5)$ \\
\hline No & $69678(98.5)$ & $19653(88.5)$ \\
\hline Time to claim approval, median (Q1-Q3), wk & $1.0(0.9-1.9)$ & $2.4(1.1-5.6)$ \\
\hline
\end{tabular}




\section{OPEN}

differences in effect sizes: if the HRs did not vary by 0.20 or more across the different models, we presented the effect sizes from the overall model; if the HRs varied by 0.20 or more, we presented the effects of the respective independent variable(s) separately for each clinical subgroup.

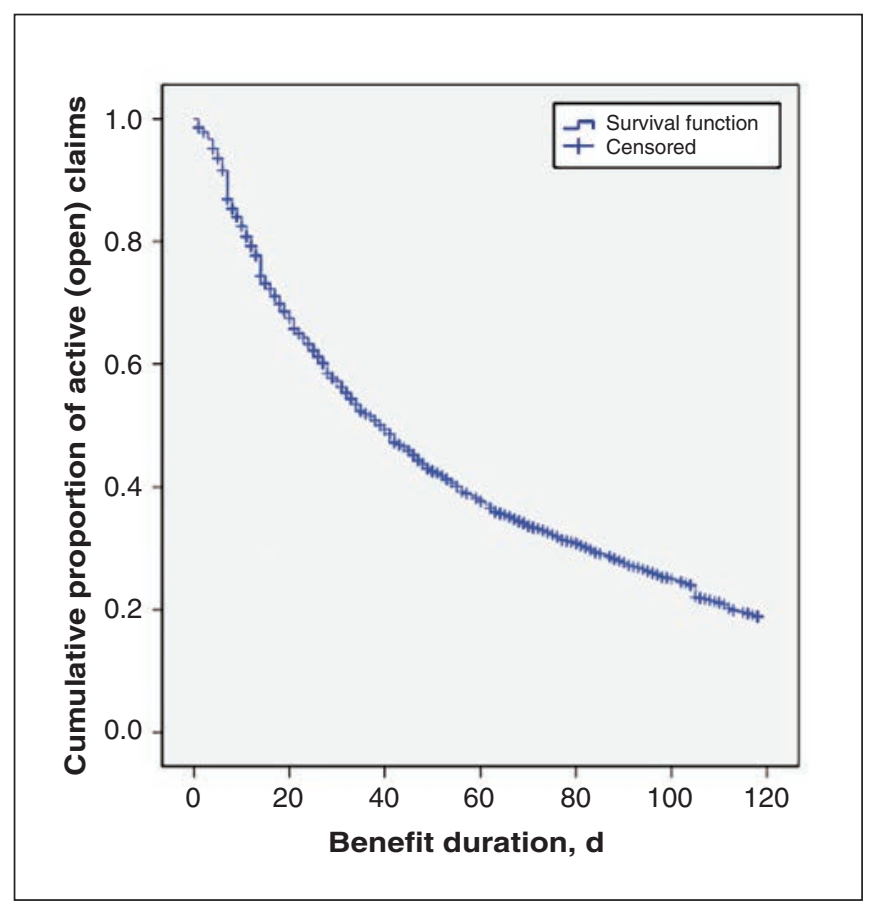

Figure 1: Kaplan-Meier (survival) curve of short-term disability duration.

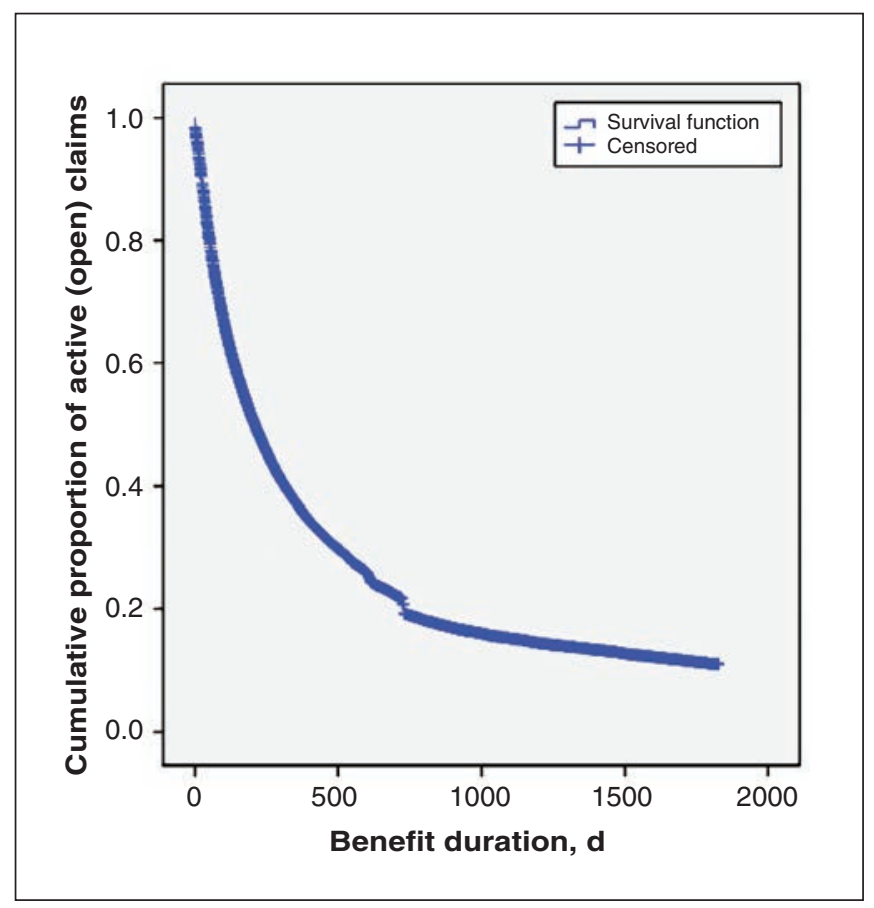

Figure 2: Kaplan-Meier (survival) curve of long-term disability duration.
We conducted all statistical analyses using SAS software, version 9.3 (SAS Institute) and created plots using IBM SPSS Statistics, version 20.0.

\section{Ethics approval}

The Hamilton Integrated Research Ethics Board approved our study.

\section{Results}

Our study sample consisted of 70776 short-term and 22205 long-term disability claims. The sample comprised claims from all Canadian provinces and territories, although most were from Quebec $(n=75817)$. Table 1 presents the baseline characteristics of our study sample.

\section{Short-term disability}

Of 70776 short-term disability claims, 57158 (80.8\%) were closed before 17 weeks, and 13618 (19.2\%) were censored (Figure 1).

Our adjusted Cox regression analysis showed associations between older age (HR 0.87, 99\% CI 0.86-0.88, per decade), higher predisability salary (HR $0.95,99 \%$ CI $0.92-0.99$, per $\$ 1000$ per week), female sex (HR 0.88, 99\% CI 0.85-0.90), heavy job demands (HR 0.93, 99\% CI 0.90-0.96), report of comorbidity (HR $0.65,99 \%$ CI $0.63-0.67$ ), attending an independent medical evaluation (HR 0.23, 99\% CI 0.20-0.27), receipt of rehabilitation therapy (HR $0.21,99 \%$ CI $0.18-0.25)$ and longer time to claim approval (HR 0.95 , 99\% CI 0.95 0.96 , per week) and longer short-term disability claim duration (Table 2). Claimants with psychological disorders who resided in Quebec were more likely (HR 0.69, 99\% CI 0.63$0.74)$ to have longer short-term disability claims than those from other provinces; conversely, claimants with musculoskeletal complaints and other illnesses from Quebec were more likely to have shorter short-term disability claims compared with claimants from elsewhere in Canada (HR 1.15, 99\% CI 1.10-1.22 for musculoskeletal complaints; HR 1.08, 99\% CI $1.04-1.12$ for other illnesses).

\section{Long-term disability}

Of 22205 long-term disability claims, 17474 (78.7\%) were closed when we extracted our data, and 4731 (21.3\%) were censored (Figure 2).

Our adjusted regression analysis showed older age (HR 0.82, 99\% CI 0.80-0.83, per decade), female sex (HR 0.94, 99\% CI 0.90-0.98), heavy job demands (HR 0.94, 99\% CI $0.89-0.99$ ), report of comorbidity (HR $0.75,99 \%$ CI 0.72 0.79 ), attending an independent medical evaluation (HR $0.57,0.53-0.61$ ), receipt of rehabilitation therapy (HR 0.55 , 99\% CI 0.52-0.59) and longer time to claim approval (HR $0.93,0.92-0.94$, per week) were associated with longer longterm claim duration (Table 3). Furthermore, we found Quebec residency was associated with shorter long-term claim duration, although the size of the effect varied according to claimants' clinical condition (HR 1.54, 99\% CI 1.38-1.71 for psychological disorders; HR 1.39, 99\% CI 1.28-1.51 for 
musculoskeletal complaints; HR 1.19, 99\% CI 1.10-1.28 for other illnesses).

Table 4 presents the comparison between our anticipated direction of effects and the observed results.

\section{Interpretation}

For both short- and long-term disability claims, older age, female sex, heavy job demands, presence of comorbidity, attending an independent medical evaluation, receipt of rehabilitation therapy and longer time to claim approval were associated with longer claim duration. Higher predisability salary was associated with longer short-term claim duration. Residing in Quebec was associated with longer short-term claim duration for claimants with psychological disorders, but shorter short-term claim duration for claimants with muscu-

\begin{tabular}{|c|c|c|}
\hline Factor & $\mathrm{HR}(99 \% \mathrm{Cl})$ & $p$ value \\
\hline Age (per decade) & $\begin{array}{c}0.87 \\
(0.86-0.88)\end{array}$ & $<0.0001$ \\
\hline Salary (per $\$ 1000 / w k$ ) & $\begin{array}{c}0.95 \\
(0.92-0.99)\end{array}$ & 0.0003 \\
\hline \multicolumn{3}{|l|}{ Sex } \\
\hline Female v. male (reference) & $\begin{array}{c}0.88 \\
(0.85-0.90)\end{array}$ & $<0.0001$ \\
\hline \multicolumn{3}{|l|}{ Job demands } \\
\hline Heavy v. sedentary (reference) & $\begin{array}{c}0.93 \\
(0.90-0.96)\end{array}$ & $<0.0001$ \\
\hline Light v. sedentary (reference) & $\begin{array}{c}0.99 \\
(0.97-1.02)\end{array}$ & 0.5 \\
\hline \multicolumn{3}{|l|}{ Province } \\
\hline $\begin{array}{l}\text { Quebec v. other (reference) by } \\
\text { psychological disorder }\end{array}$ & $\begin{array}{c}0.69 \\
(0.63-0.74)\end{array}$ & $<0.0001$ \\
\hline $\begin{array}{l}\text { Quebec v. other (reference) by } \\
\text { musculoskeletal complaint }\end{array}$ & $\begin{array}{c}1.15 \\
(1.10-1.22)\end{array}$ & 0.008 \\
\hline $\begin{array}{l}\text { Quebec v. other (reference } \\
\text { group) by other illness }\end{array}$ & $\begin{array}{c}1.08 \\
(1.04-1.12)\end{array}$ & 0.0003 \\
\hline \multicolumn{3}{|l|}{ Comorbidity } \\
\hline Yes v. no (reference group) & $\begin{array}{c}0.65 \\
(0.63-0.67)\end{array}$ & $<0.0001$ \\
\hline \multicolumn{3}{|c|}{ Attendance at SSQ-arranged independent medical evaluation } \\
\hline Yes v. no (reference group) & $\begin{array}{c}0.23 \\
(0.20-0.27)\end{array}$ & $<0.0001$ \\
\hline \multicolumn{3}{|l|}{ Receipt of SSQ-funded rehabilitation } \\
\hline Yes v. no (reference group) & $\begin{array}{c}0.21 \\
(0.18-0.25)\end{array}$ & $<0.0001$ \\
\hline Duration of claim approval (wk) & $\begin{array}{c}0.95 \\
(\ldots 0.95-0.96)\end{array}$ & $<0.0001$ \\
\hline
\end{tabular}

loskeletal complaints and other illnesses. For long-term disability claims, residing in Quebec was associated with shorter claim duration across all clinical conditions.

Our findings are consistent with our previous study, which suggested older age, female sex (short-term disability claims only), higher salary and comorbidity were associated with longer claim duration among claimants with depression. ${ }^{4}$ In our previous study, prolonged time to claim approval was only associated with longer long-term claim duration; in the current study, however, longer claim approval was associated with longer duration of both short- and long-term disability claims. Minimizing time to claim approval may be a promising target for reducing claim duration. Furthermore, longterm disability claims may benefit from the continuity of care when the same provider has overseen the management of the short-term disability claim.

Table 3: Determining factors predictive of time to long-term disability benefits duration based on multivariable Cox regression analysis

\begin{tabular}{|lcc|}
\hline Factor & HR $(99 \%$ Cl) & $p$ value \\
\hline Age (per decade) & $\begin{array}{c}0.82 \\
(0.80-0.83)\end{array}$ & $<0.0001$ \\
\hline Salary (per \$1000/wk) & 1.02 & 0.4 \\
& $(0.97-1.08)$ & \\
\hline Sex & & \\
\hline Female v. male (reference) & 0.94 & 0.0001 \\
& $(0.90-0.98)$ & \\
\hline Job demands & & \\
\hline Heavy v. sedentary (reference) & $\begin{array}{c}0.94 \\
\end{array}$ & 0.002 \\
\hline Light v. sedentary (reference) & $(0.89-0.99)$ & \\
\hline & $\begin{array}{c}1.02 \\
(0.98-1.07)\end{array}$ & 0.2 \\
\hline
\end{tabular}

\section{Province}

$\begin{array}{lcc}\begin{array}{l}\text { Quebec vs. other (reference) by } \\ \text { psychological disorder }\end{array} & \begin{array}{c}1.54 \\ (1.38-1.71)\end{array} & <0.0001 \\ \begin{array}{l}\text { Quebec v. other (reference) by } \\ \text { musculoskeletal compliant }\end{array} & \begin{array}{c}1.39 \\ (1.28-1.51)\end{array} & 0.0003 \\ \begin{array}{l}\text { Quebec v. other (reference) by } \\ \text { other illness }\end{array} & \begin{array}{c}1.19 \\ (1.10-1.28)\end{array} & <0.0001 \\ \begin{array}{l}\text { Comorbidity } \\ \text { Yes v. no (reference) }\end{array} & 0.75 & <0.0001 \\ & (0.72-0.79) & \end{array}$

Attendance at SSQ-arranged independent medical evaluation

Yes v. no (reference) $\begin{array}{cc}0.57 & <0.0001\end{array}$

Receipt of SSQ-funded rehabilitation

\begin{tabular}{ccc} 
Yes v. no (reference) & 0.55 & $<0.0001$ \\
& $(0.52-0.59)$ & \\
\hline Duration of claim approval (wk) & 0.93 & $<0.0001$ \\
& $(0.92-0.94)$ &
\end{tabular}

Note: $\mathrm{Cl}=$ confidence interval; $\mathrm{HR}=$ hazard ratio. $\mathrm{HR}>1$ is associated with shorter claim duration; $\mathrm{HR}<1$ is associated with longer claim duration. 


\section{OPEN}

Table 4: Comparison between predictors associated with claim duration for short-term disability versus long-term disability

\begin{tabular}{|c|c|c|c|}
\hline Predictor & Short-term disability & Long-term disability & Anticipated direction \\
\hline Older age & $(-)$ & $(-)$ & $(-)$ \\
\hline Female sex (v. male) & $(-)$ & $(-)$ & $(-)$ \\
\hline Higher salary & $(-)$ & NS & $(-)$ \\
\hline Heavy job demands (v. sedentary) & $(-)$ & $(-)$ & $(-)$ \\
\hline Light job demands (v. sedentary) & NS & NS & $(-)$ \\
\hline Quebec residency (v. elsewhere) & $\begin{array}{l}(-) \text { for claimants with } \\
\text { psychological disorders } \\
(+) \text { for claimants with } \\
\text { musculoskeletal complaints } \\
\text { and other illness }\end{array}$ & $(+)$ & $\begin{array}{l}\text { (-) for short-term disability } \\
(+) \text { for long-term disability }\end{array}$ \\
\hline Presence of comorbidity (v. no comorbidity) & $(-)$ & $(-)$ & $(-)$ \\
\hline $\begin{array}{l}\text { Attendance at SSQ-arranged independent } \\
\text { medical evaluation ( } v \text {. no attendance) }\end{array}$ & $(-)$ & $(-)$ & $(-)$ \\
\hline $\begin{array}{l}\text { Receipt of SSQ-funded rehabilitation (v. no } \\
\text { receipt of rehabilitation) }\end{array}$ & $(-)$ & $(-)$ & $(+)$ \\
\hline Longer time to claim approval & $(-)$ & $(-)$ & $(-)$ \\
\hline
\end{tabular}

We previously found that residing in Quebec (v. Ontario) was associated with longer short-term disability claim duration, but shorter long-term disability claim duration. ${ }^{4}$ Now, we report a similar association among SSQ claimants with psychological disorders who resided in Quebec compared with those residing elsewhere in Canada. Among claimants with musculoskeletal complaints and other illnesses, however, Quebec residency was associated with shorter short-term and longterm disability benefit duration. Systematic differences in claim management policies and processes in Quebec may explain variation in claim duration. For example, Quebec is the only province with a civil code; the rest of Canada uses the common law. Under the civil code in Quebec, should claimants wish to commence a legal action against their disability insurer for terminating a claim, they must pay a retainer to obtain counsel; in the common law provinces, there is no such requirement. Furthermore, there are no substantial damage awards given under the civil code, whereas in the common law provinces, there is case law with damage awards in excess of $\$ 1$ million. These policies may provide greater incentive for litigation outside of Quebec, which is associated with prolonged disability. ${ }^{7-9}$

Our results are consistent with previous evidence that suggests heavy physical job demands are associated with delayed recovery. ${ }^{10-15}$ Contrary to our hypotheses, however, we found claimants who attended an independent medical evaluation or received rehabilitation service are more likely to experience prolonged claim duration. We were unable to adjust for injury or illness severity, and it is possible these interventions are largely directed toward claimants who are sicker or more seriously injured, and would therefore experience longer claim duration.

\section{Strengths and limitations}

Strengths of our study include a priori selection of independent variables for our regression models, including the anticipated direction of effects. Other strengths include no missing data, and correction of all identifiable data errors and inconsistencies.

Limitations of our study include the retrospective design, which did not allow us to investigate certain variables in detail, such as reasons for arranging independent medical evaluations and rehabilitation. In addition, a number of variables known to affect claim duration were unavailable, such as injury or illness severity. Our primary outcome, disability claim duration, underestimates total disability duration, because the start date of benefits may not coincide with the start of the disability, particularly among claimants who qualify for long-term disability benefits, but have to wait before receiving payments (the elimination period). Furthermore, claim closure is a surrogate for patient-important outcomes, such as functional recovery and sustained return to work. ${ }^{4}$ Most of the claims in our study sample were from a single province, which may threaten the external validity of our work. In addition, our results may not be generalizable to people who present with work-related disability, because those claims would be submitted to provincial compensation boards. Finally, our analyses did not account for the effects of clustering arising from claimants who may have multiple disabilities over the study period and who would have contributed more than 1 claim to our data set. The direction of bias associated with more than 1 claim from a person is difficult to predict: it could lead to over- or underestimates of the size of association.

\section{Conclusion}

We found 2 previously untested predictors of the duration of short- and long-term disability benefits - attendance at an independent medical evaluation and receipt of rehabilitation. Furthermore, claimants' age, sex, job demands, presence of comorbidity, attendance at an independent medical evaluation, receipt of rehabilitation therapy and time to claim 
approval were consistently predictive of benefits duration, irrespective of clinical condition. Quebec residency was associated with longer short-term claim duration among workers with psychological disorders, but shorter short-term claim duration among those with musculoskeletal complaints and other illnesses. For long-term disability claims, residing in Quebec was associated with shorter claim duration, although the size of the association differed across clinical conditions. Our results provide a direction for randomized trials that address determinants of returning to work. Modifiable factors, such as time to claim approval, are subject to interventions that may decrease claim duration. Nonmodifiable risk factors could allow identification of claimants at high risk of prolonged recovery who might then be targeted for interventions, like psychotherapy, for which preliminary evidence suggests possible benefit.

\section{References}

1. Number and percentage with and without disabilities, aged 15 years or older, Canada, provinces and territories, 2012 [table]. Ottawa: Statistics Canada; 2015. Available: www.statcan.gc.ca/pub/89-654-x/2015001/tbl/tbl01-eng.htm (accessed 2017 Jan. 30).

2. Canadian Survey on Disability (CSD). Ottawa: Statistics Canada; 2012. Available: www.statcan.gc.ca/csd (accessed 2017 Jan. 30).

3. Days lost per worker due to illness or disability, by sex, by province (both sexes) [table]. Ottawa: Statistics Canada; 2015. Available: http://www.statcan.gc.ca/ tables-tableaux/sum-som/101/cst01/health47a-eng.htm (accessed 2017 Jan. 30).

4. Ebrahim S, Guyatt GH, Walter SD, et al. Association of psychotherapy with disability benefit claim closure among patients disabled due to depression. PLoS One 2013;8:e67162.

5. von Elm E, Altman DG, Egger M, et al. STROBE Initiative. The Strengthening the Reporting of Observational Studies in Epidemiology (STROBE) statement: guidelines for reporting observational studies. Lancet 2007;370:1453-7.

6. Peduzzi P, Concato J, Feinstein AR, et al. Importance of events per independent variable in proportional hazards regression analysis. II. Accuracy and precision of regression estimates. F Clin Epidemiol 1995;48:1503-10.

7. Casey PP, Feyer AM, Cameron ID. Associations with duration of compensation following whiplash sustained in a motor vehicle crash. Injury 2015;46: $1848-55$
8. Bernacki EJ, Tao XG. The relationship between attorney involvement, claim duration, and workers' compensation costs. 7 Occup Environ Med 2008; 50:1013-8.

9. Suter PB. Employment and litigation: improved by work, assisted by verdict. Pain 2002;100:249-57.

10. de Jonge J, Spoor E, Sonnentag S, et al. "Take a break?!" Off-job recovery, job demands, and job resources as predictors of health, active learning, and creativity. Eur 7 Work Organ Psychol 2012;21:321-48.

11. Kuper H, Marmot M. Job strain, job demands, decision latitude, and risk of coronary heart disease within the Whitehall II study. 7 Epidemiol Community Health 2003;57:147-53.

12. Sonnentag S, Zijlstra FR. Job characteristics and off-job activities as predictors of need for recovery, well-being, and fatigue. 7 Appl Psychol 2006;91:330-50.

13. de Lange AH, Kompier MA, Taris TW, et al. A hard day's night: a longitudinal study on the relationships among job demands and job control, sleep quality and fatigue. 7 Sleep Res 2009;18:374-83.

14. Bakker AB, Demerouti E, De Boer E, et al. Job demands and job resources as predictors of absence duration and frequency. 7 Vocat Behav 2003;62:341-56.

15. Stansfeld S, Candy B. Psychosocial work environment and mental health - a meta-analytic review. Scand 7 Work Environ Health 2006;32:443-62.

Affiliations: Department of Clinical Epidemiology and Biostatistics (Mulla, Heels-Ansdell, Guyatt, Busse), McMaster University, Hamilton, Ont.; Outcomes Research Consortium (Mulla), Cleveland, OH, USA; Michael G. DeGroote Institute for Pain Research and Care (MakossoKallyth; Busse); Departments of Anesthesia (Makosso-Kallyth, Busse), McMaster University, Hamilton, Ont.; SSQ, Life Insurance Company Inc. (St-Hilaire, Munsch, Gove), Toronto, Ont.; Department of Medicine (Guyatt), McMaster University, Hamilton, Ont.

Contributors: All of the authors contributed substantially to the conception and design, acquisition of data, or analysis and interpretation of data. Sohail Mulla drafted the manuscript, and the remaining authors revised it critically for important intellectual content. All of the authors gave final approval of the version to be published, and agreed to act as guarantors of the work.

Funding: Sohail Mulla received a Mitacs Accelerate Doctoral Award that was partially funded by SSQ Financial Inc.

Acknowledgements: The authors thank Dr. Norman Buckley, Dr. Shanil Ebrahim, and Dr. Lehana Thabane for helpful discussions.

Supplemental information: For reviewer comments and the original submission of this manuscript, please see www.cmajopen.ca/content/5/1/ E109/suppl/DC1 